\title{
Editorial
}

\section{Recent Developments on Summability Theory and Its Applications}

\author{
Mikail Et, ${ }^{1,2}$ Mohammad Mursaleen, ${ }^{3}$ Syed Abdul Mohiuddine, ${ }^{4}$ \\ Mahmut Işık, ${ }^{5}$ Jeff Connor, ${ }^{6}$ and Feyzi Başar ${ }^{7}$ \\ ${ }^{1}$ Department of Mathematics, Firat University, 23119 Elazı̆̆, Turkey \\ ${ }^{2}$ Department of Mathematics, Siirt University, 56100 Siirt, Turkey \\ ${ }^{3}$ Department of Mathematics, Aligarh Muslim University, Aligarh 202002, India \\ ${ }^{4}$ Operator Theory and Applications Research Group, Department of Mathematics, Faculty of Science, \\ King Abdulaziz University, P.O. Box 80203, Jeddah 21589, Saudi Arabia \\ ${ }^{5}$ Faculty of Education, Harran University, Osmanbey Campus, 63190 Şanliurfa, Turkey \\ ${ }^{6}$ Department of Mathematics, Ohio University, Athens, OH 45701, USA \\ ${ }^{7}$ Department of Mathematics, Faculty of Arts and Sciences, Fatih University, Hadımköy Campus, \\ Büyükçekmece, 34500 Istanbul, Turkey
}

Correspondence should be addressed to Mikail Et; mikailet68@gmail.com

Received 31 May 2015; Accepted 3 June 2015

Copyright (C) 2015 Mikail Et et al. This is an open access article distributed under the Creative Commons Attribution License, which permits unrestricted use, distribution, and reproduction in any medium, provided the original work is properly cited.

The aim of this special issue is to focus on the latest developments and achievements in summability theory such as sequence spaces and their geometry, statistical summability and statistical approximation, almost summability, fuzzy sequence spaces, matrix summability, compact matrix operators between sequence spaces, infinite systems of differential and integral equations in sequence spaces, and various applications. The theory of sequence spaces is a powerful tool for obtaining positive results concerning Schauder bases and plays a fundamental role in creating the basis of several investigations conducted in nonlinear analysis.

The research papers in this special issue cover various topics like uniform convergence of sequences and series of fuzzy-valued functions, stability of functional equations, performance on ICI self-cancellation in FFT-OFDM and DCTOFDM system, paranormed sequence spaces and related duals over the non-Newtonian complex field, Fourier expansions with polynomial terms, statistical summability methods of order $\beta$ of sequences of fuzzy numbers, fixed point theorems for contractive mappings, and star-shaped sets in manifolds. We believe that the results presented in this issue will be a source of inspiration for researchers working in summability theory and related areas of mathematics.

\section{Acknowledgments}

The guest editors of this special issue would like to express their gratitude to the authors who have submitted papers for consideration. The editors thank all the contributors and colleagues who did the refereeing work very sincerely.

Mikail Et

Mohammad Mursaleen Syed Abdul Mohiuddine Mahmut Işık Jeff Connor Feyzi Başar 


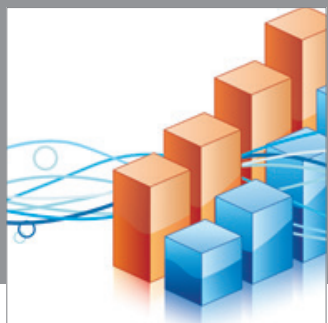

Advances in

Operations Research

mansans

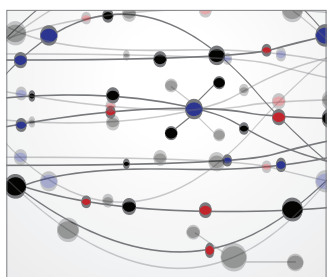

The Scientific World Journal
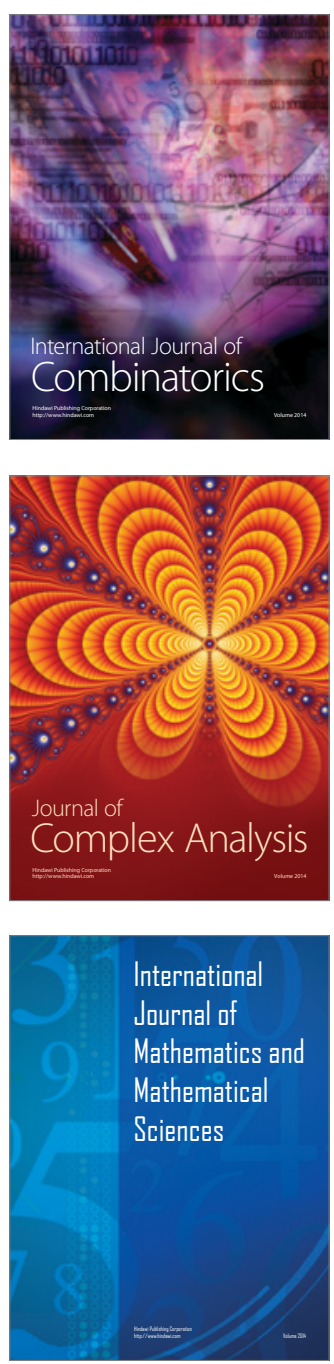


Submit your manuscripts at http://www.hindawi.com


Journal of

Function Spaces

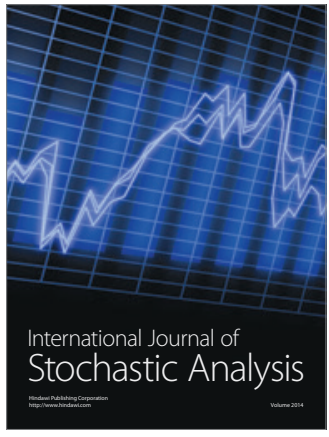


